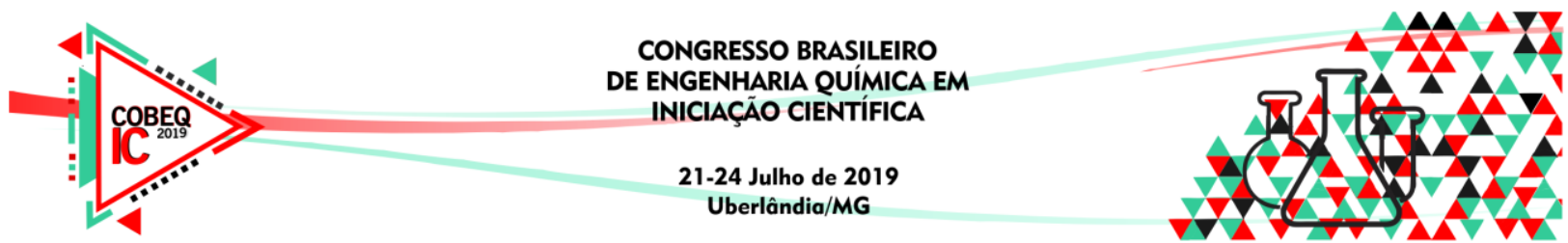

\title{
SÍNTESE DE LIPÍDEOS ESTRUTURADOS EM REATOR DE LEITO FIXO EMPREGANDO LIPOZYME RM IM
}

\author{
M.F. RODRIGUES ${ }^{1}$, I. S. C COZENTINO ${ }^{2}$, D. C. U CAVALLINI ${ }^{2}$,A.V. PAULA ${ }^{1}$ \\ ${ }^{1}$ Departamento de Bioprocessos e Biotecnologia, Faculdade de Ciências Farmacêuticas de \\ Araraquara, Universidade Estadual Paulista Júlio de Mesquita Filho - UNESP \\ 2 Departamento de Alimentos e Nutrição, Faculdade de Ciências Farmacêuticas de \\ Araraquara, Universidade Estadual Paulista Júlio de Mesquita Filho - UNESP \\ E-mail para contato: maridfr05@gmail.com, ariela.veloso@unesp.br
}

\begin{abstract}
RESUMO - Um dos grandes desafios da industria de alimentos na moderna ainda é a busca por alimentos mais saudáveis e benéficos a saúde, em vista do crescente número de doenças causadas por uma má alimentação. Dentre esses, há um grande interesse na modificação de óleos e gorduras visando a obtenção de lipídeos estruturados, os quais, para a alimentação destacam-se os triglicerídeos dietéticos, que apresentam um elevado valor nutracêutico comparado ao atuais óleos no mercado. Os triglicerídeos dietéticos do tipo MLM, contém ácidos graxos de cadeira média (M) na posição sn-1 e sn-3 e um ácido graxo de cadeia longa na posição sn-2, podendo ser sintetizados através da acidólise enzimática de óleos. O presente trabalho teve como objetivo sintetizar o triglicerídeos dietético do tipo MLM por meio de acidólise enzimática do óleo de uva com ácido cáprico, utilizando a Lipozyme RM IM em reator de leito fixo.
\end{abstract}

\section{INTRODUÇÃO}

Os óleos e gorduras apresentam um papel fundamental na nutrição do ser humano, devido a seus efeitos fisiológicos, metabólicos ou nutritivos, podendo eles fornecer além de uma fonte de energia, ácidos graxos essenciais (Liu, 2015). No entanto, uma ingestão em excesso pode acarretar em prejuízos a saúde, levando a doenças como a obesidade e problemas cardíacos. Nos últimos anos é crescente a procura do consumidor por produtos mais saudáveis, que apresentem boas propriedades nutricionais (Cao, 2013).

Junto à nova demanda do mercado há uma grande busca pelo desenvolvimento da tecnologia de modificação dos óleos e gorduras, na expectativa da criação de um produto com novas características que se adeque a uma determinada aplicação. No aspecto nutricional os óleos devem desempenhar seu papel de fornecimento de ácido graxos essenciais, transporte de vitaminas lipossolúveis e aporte energético, entretanto serem o menos nocivo a saúde e com menor valor calórico.

$\mathrm{Na}$ atualidade, o desenvolvimento de métodos químicos ou enzimáticos para a modificação dos ácidos graxos na molécula de glicerol, transformando-a em lipídeos estruturados, triacilgliceróis (TAGs), vem sendo de extrema importância para a indústria alimentícia, pois geram óleos e gorduras de elevado valor nutricional, cumprindo a nova demanda atual do mercado (AKOH, 2005). 


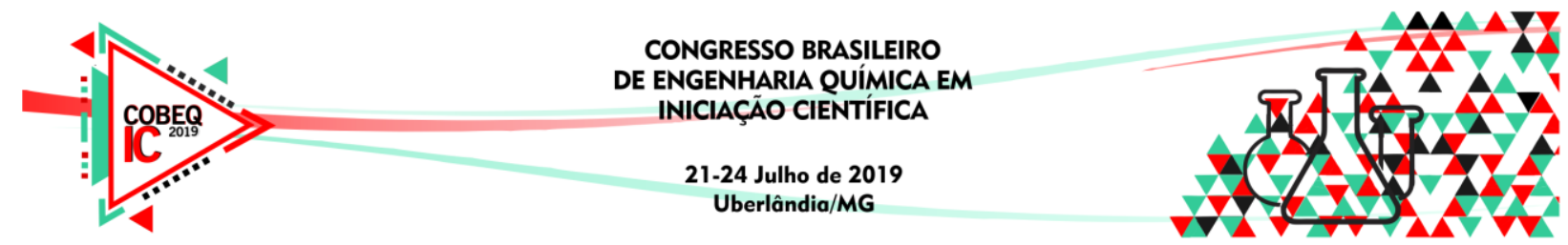

Dentre esses novos óleo e gorduras modificados o triglicerídeo do tipo MLM ganha grande destaque, pois apresenta um baixo índice calórico, evitando problemas como o sobrepeso. Esse triglicerídeo apresenta dois ácidos graxos de cadeia media (M) nas posições sn-1 e sn-3 e um de cadeira longa (L) na posição sn-2 (Bassan, 2017). Esse triglicerídeo pode ser sintetizado a partir de diversos óleos vegetais, destacando-se entre eles o óleo de semente de uva, composto por uma expressiva quantidade de gorduras mono e poli-insaturadas (72 a $76 \%$ ), além de seu alto valor nutricional.

A produção dos lipídios estruturados pela via enzimática apresenta diversas vantagens, com menores quantidades de subprodutos tóxicos ao meio ambiente quando comparados a produção por vias químicas. Para essa conversão, destaca-se a lipase, que apresenta especificidade na reação, incorporando os ácidos graxos nas posições desejadas do glicerol, gerando um produto final com boas propriedades funcionais (Akanbi, 2015).

Essas enzimas são aplicadas em um sistema de conversão denominados biorreatores. Os principais tipos de biorreator descritos em literatura são tanque agitado operado em batelada, tanque agitado contínuo, leito fluidizado e leito fixo (Poppe et al, 2015). Dentre esses, o biorreator de leito fixo vem sendo muito pesquisados na atualidade para conversões com lipases, como exemplo Poppe e seus colaboradores (2018), que utilizaram um combo de lipases comercial para a modificação de óleo residual em reator enzimático de leito fixo, pois, devido a sua simplicidade de operação possui um baixo custo de construção e manutenção, assim como é um equipamento que apresenta grande capacidade para conversão e eficiência (Silva, 2013).

Nesse contexto, o presente trabalho tem como principal objetivo a síntese de triglicerídeos modificados do tipo MLM por meio de acidólise enzimática do óleo de uva, utilizando a lipase Lipozyme RM IM em reator de leito fixo.

\section{METODOLOGIA}

Foram efetuadas reações de acidólise entre o óleo de uva e o ácido graxo cáprico $\left(\mathrm{C}_{10}\right)$, mistura com razão molar 1:3 em reator de coluna leito fixo (Figura 1), operando no modo contínuo em banho termostatizado, catalisado pela lipase imobilizada (Lipozyme RM IM), conforme imagem 2. O interior da coluna foi preenchido com massa de $16 \mathrm{~g}$ de biocatalisador, conforme determinado em estudos prévios. As dimensões do reator são: altura $h$ de $18,00 \mathrm{~cm}$ e diâmetro $D$ de $2 \mathrm{~cm}$, correspondendo a um volume útil de aproximadamente $34 \mathrm{~mL}$. A vazão empregada foi de $6 \mathrm{ml} / \mathrm{h}$ (tempo espacial $=7 \mathrm{~h}$ ), segundo a esquação 1 . A mistura reacional (óleo de uva e ácido cáprico) foi bombeada continuamente através do sistema pela ação de uma bomba (Figura 2). A reação ocorreu sob temperatura de $45^{\circ} \mathrm{C}$, com base em trabalhos prévios realizados por Bassan (2017).

$$
t=\frac{V_{\text {ưtil }}}{Q_{\mathrm{w} \Omega l}}(1)
$$




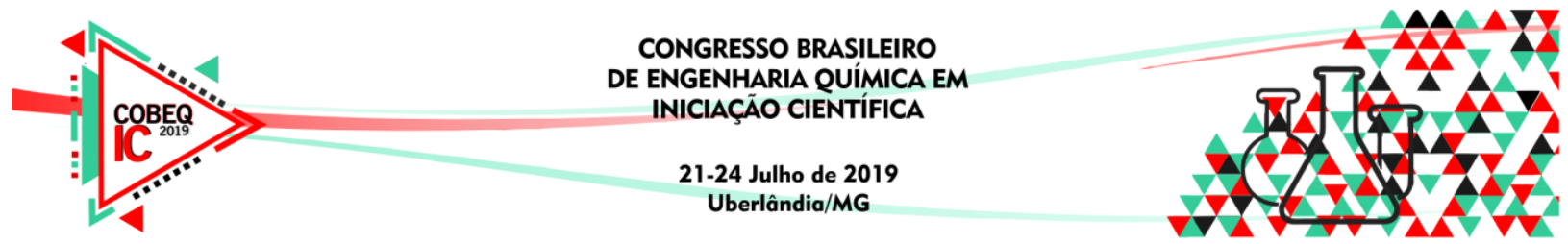

Figura 1- Reator de coluna que será utilizado na reação.

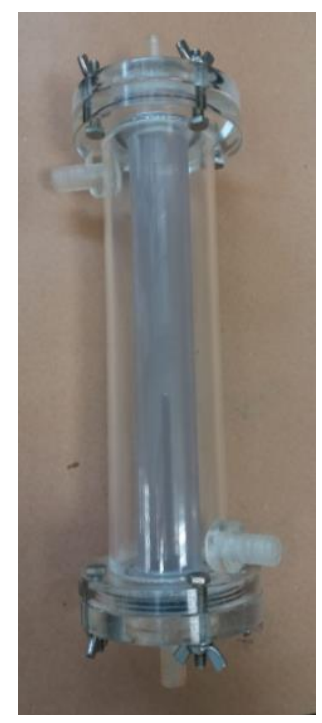

Figura 2 - Sistema de reação com leito fixo para realização de testes preliminares.

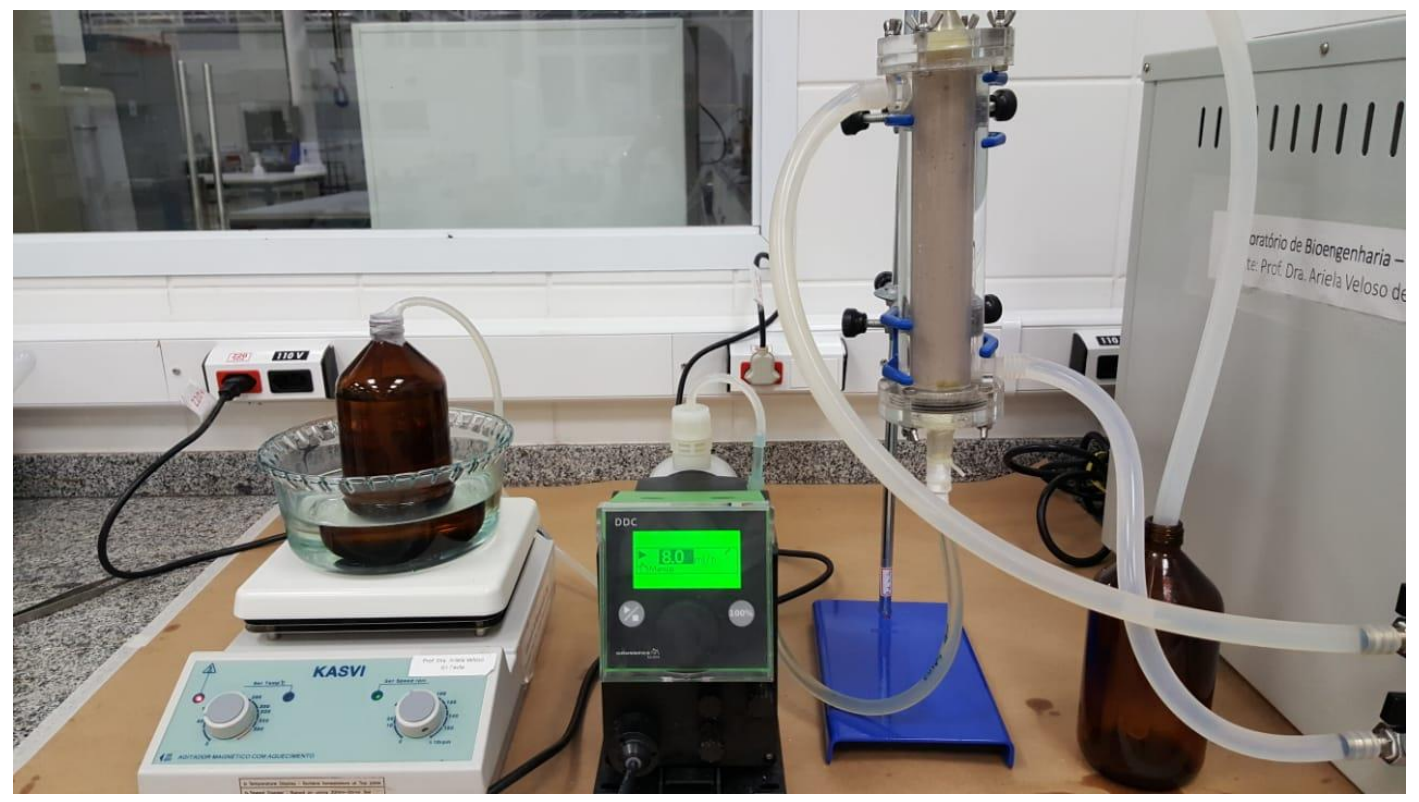

$\mathrm{O}$ ensaio foi conduzido até que o sistema atingisse o estado estacionário e permanecesse neste por pelo menos três tempos de residência. Foram preparados $500 \mathrm{~mL}$ de meio contendo óleo de semente de uva e ácido cáprico (razão molar 1:3). 


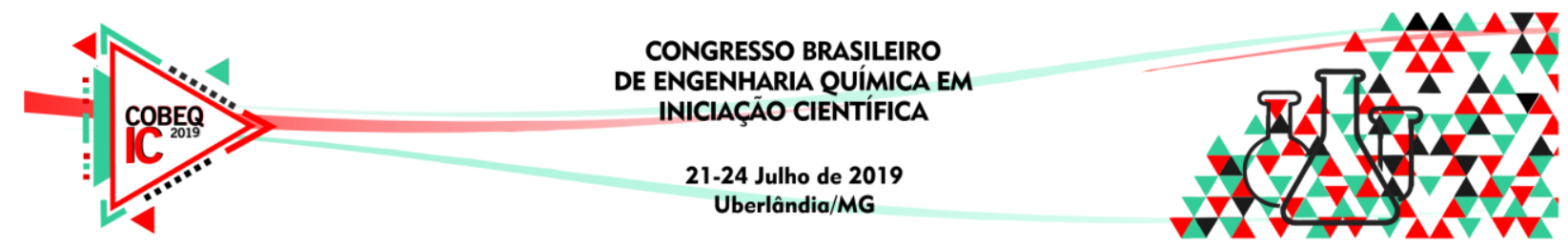

As amostras periódicas foram analisadas com relação ao grau de incorporação do ácido graxo. O grau de incorporação (GI) será calculado de acordo com a equação 2 (Casasgodoy et al., 2013).

$$
G I(\%)=\frac{M F A}{M T} * 100
$$

Onde: MFA é o número de mols de ácidos graxos de cadeia média (C8:0 ou C10:0) no triglicerídeos e MT é o número de mols totais de ácidos graxos no triglicerídeo.

\section{RESULTADOS}

Para o acompanhamento da reação de acidólise, foram retiradas amostras em diferentes temos reacionais, a fim de se avaliar o grau de incorporação (GI, \%) do ácido cáprico no óleo de uva. Conforme a figura 4, pode-se observar que o grau de incorporação foi crescente durante as primeiras 54 horas de reação, e apresentaram um grau de incorporação muito próximo durante o resto do tempo reacional.

Figura 4 - Grau de incorporação (\%) em função do tempo.

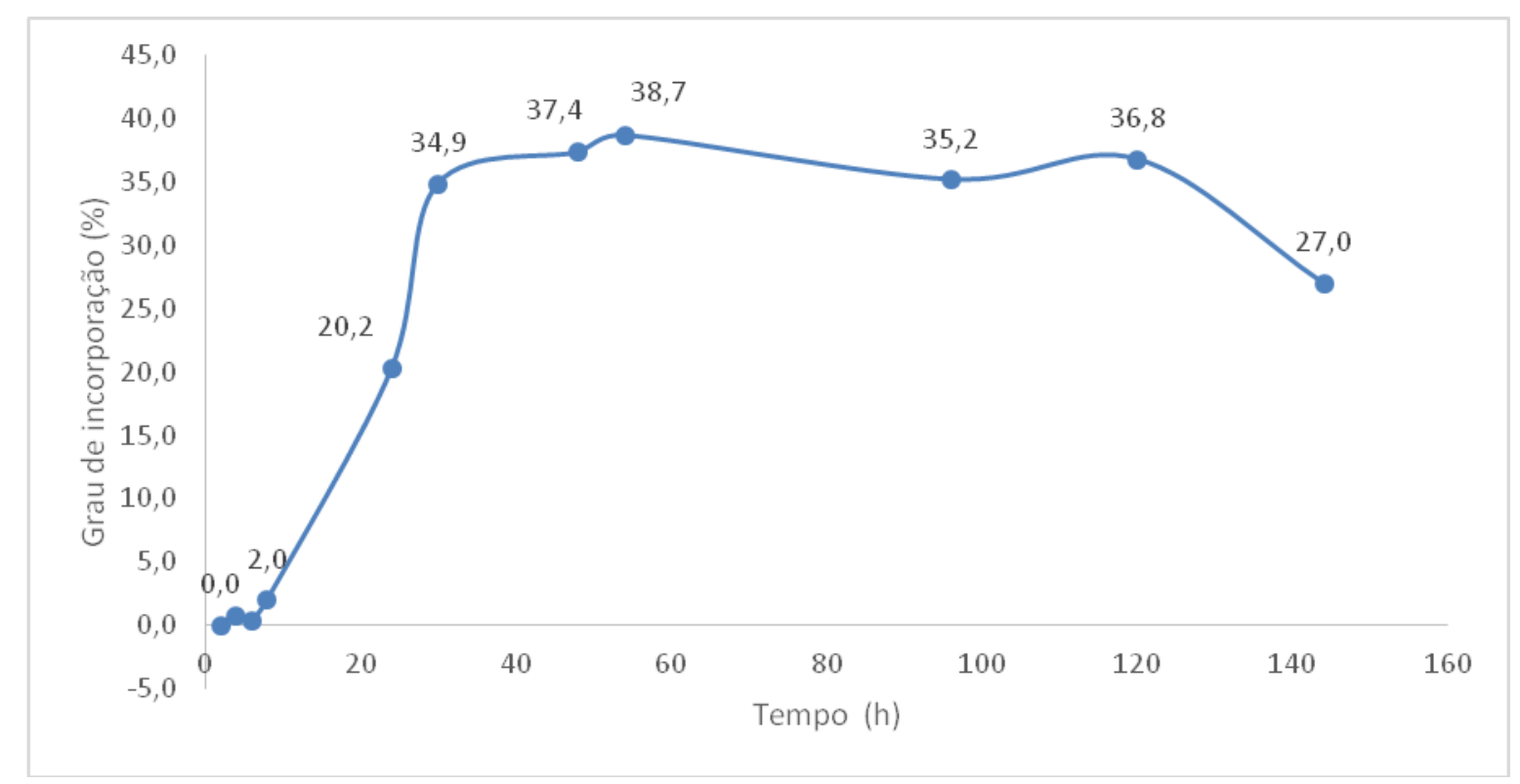

O cálculo do grau de incorporação (GI, \%) é importante pois é um indicativo do sucesso da acidólise. Calculado a partir da composição em ácidos graxos da amostra, permite o acompanhamento da reação ao longo do tempo. Neste sentido, é possível afirmar, que a reação atingiu o estado estacionário após $24 \mathrm{~h}$, e o GI médio foi de $36,6 \%$, neste período.

Com esses resultados obtidos através do grau de incorporação pode-se considerar que a reação apresentou uma ótima taxa de conversão. Nunes et al (2011) que apresentou o grau de incorporação de $27,1 \%$ utilizando azeite de oliva na reação com ácido cáprico e Lipozyme 


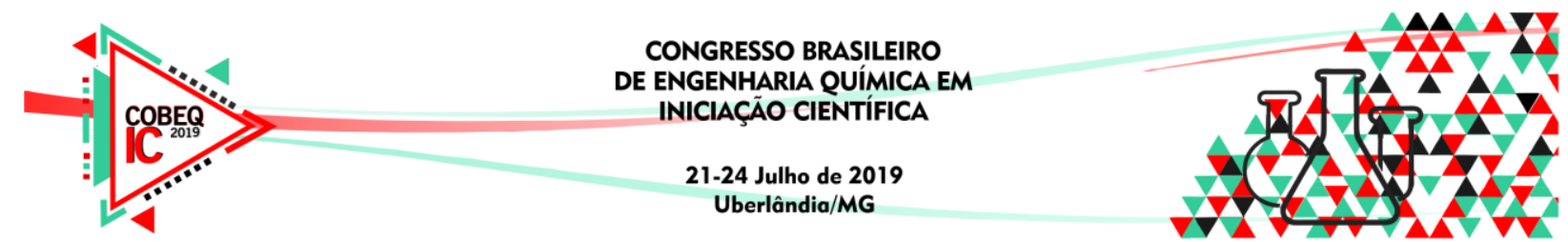

RM IM. Pesquisa realizada por Bassan (2017) ressalta que para a síntese de triglicerídeos modificados do óleo de uva o melhor resultado obtido foi de $34,53 \%$ de incorporação.

\section{CONCLUSÃO}

Estes resultados são bastantes satisfatórios e evidenciam o potencial catalítico da Lipozyme RM IM na síntese de triglicerídeos dietéticos em reator de leito fixo.

\section{AGRADECIMENTO}

Fundação de Amparo à Pesquisa do Estado de São Paulo, FAPESP (2018/23945-4) e (2017/11482-7).

\section{REFERÊNCIAS}

AKANBI T.O.; BARROW C.J.; Lipase-catalysed incorporation of EPA into meu oil: Formation and characterisation of new structured lipids. Journal of Functional Food, v. 19, p. 801-809, 2015.

AKOH, C. C; Structured and Specialty Lipids. In: AKOH, C. C; LAI, O. M. Healthful Lipids. United States of America: AOSC PRESS, 2005. 762 p. ISBN: 1-893997-51-0.

BASSAN, N.; Modificação enzimática de óleos vegetais visando à obtenção de triglicerídeos dietéticos através do emprego de reatores de tanque agitado e leito fixo Modificação enzimática de óleos vegetais visando à obtenção de triglicerídeo. 2017. Dissertação (Mestrado em Alimentos e Nutrição) - Universidade Estadual Paulista Júlio de Mesquita Filho, Araraquara. 2017.

BON, E. P. S. et al; Bioprocessos para produção de enzimas. Enzimas em Biotecnologia: Produção, Aplicações e Mercado, n. January, 2008.

CABAllero E, Soto C, Olivares A, Altamirano C. Potential use of avocado oil on structured Lipids MLM type production catalysed by commercial immobilised lípases. Plos one, 2014; 9, 1-7.

CAO Y, QI S, ZHANG Y, WAG X, YAN, B, WAG Y. Synthesis of structured lipids by LipaseCatalyzed interesterification of triacetin with camellia oil methyl esters and preliminary evaluation of their plasma lipid-lowering effect in mice. Molecules, 2013; 18,3734-3744.

LIU S, DONG X, WEI F, WANG X, LV X, ZHONG J, WU L, et al.. Ultrasonic pretreatment in catalyzed synthesis of structured lipids with high 1,3- dioleoyl-2-palmitoylglycerol content. Ultrasonics Sonochemistry, 2015; 23, $100-108$.

NUNES PA, Pires-Cabral P, Ferreira-Dias S. Production of olive oil enriched with medium chain fatty acids catalysed by commercial immobilised lipases. Food Chemistry, 2011; 127(3), 993-998. 


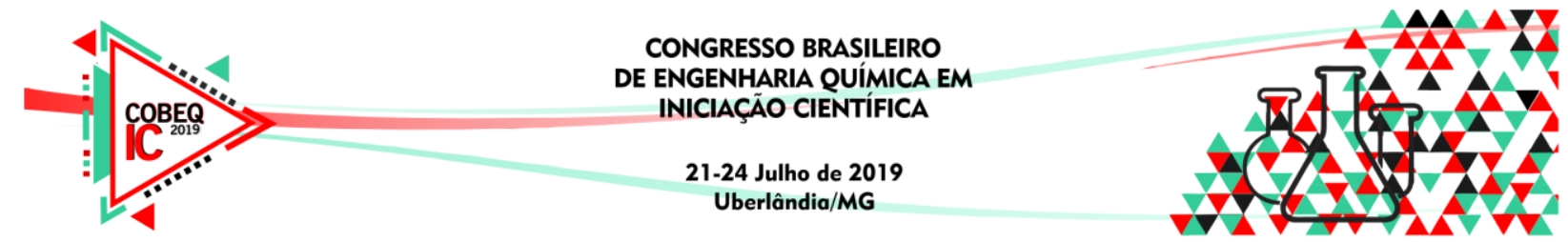

POPPE, J. K.; FERNANDEZ-LAFUENTE, R.; RODRIGUES, R. C.; AYUD, M. A. Z. Enzymatics reator for biodiesel synthesis: Presents status and future prospects. Biotechnology Advances. v. 33, n. 5, p. 511-525, Out. 2015

POPPE, J. K.; MATTE, C. R.; FREITAS, V. O.; FERNANDEZ-LAFUENTE, R.; ROXDRIGUES R. C.; AYUD, M. A. Z. Enzymatic synthesis of ethyl esters from waste oil using mixtures of lipases in a plug-flow packed-bed continuous reactor. Biotechnology Progress. Abr. 2018.

SILVA, W.C. Produção enzimática de biodiesel a partir de óleos láuricos em reatores de leito fixo duplo estágio incorporando coluna extratora de glycerol formado como subproduto. 2013. 133 p. Dissertação (Mestrado em Ciências) - Escola de Engenharia de Lorena, Universidade de São Paulo, Lorena, 2013.

SOUMANOU, M. M.; BORNSCHEUER, U. T. Improvement in lipase-catalyzed synthesis of fatty acid methyl esters from sunflower oil. Enzyme and Microbial Technology, v. 33, n. 1, p. 97-103, 2003.

WATANABE, T. et al. Optimization of Reaction Conditions for the Production of DAG Using Immobilized 1,3-Regiospecific Lipase Lipozyme RM IM. JAOCS, Journal of the American Oil Chemists' Society, v. 80, n. 12, p. 1201-1207, 2003. 